\title{
Correction to: Thinking Textile Materials from Their Nature: Ethical Materials for Fashion Design with Technological, Social, and Aesthetic Sense
}

\author{
Angela Liliana Dotor Robayo
}

\section{Correction to:}

Chapter 2 in: S. S. Muthu, M. A. Gardetti (eds.), Sustainability in the Textile and Apparel Industries, Sustainable Textiles: Production, Processing, Manufacturing \& Chemistry, https://doi.org/10.1007/978-3-030-38013-7_2

The original version of Chapter 2 was inadvertently published without updating the author's affiliation. The corrections have been incorporated in the chapter. 